\title{
Vibrations of a laboratory-scale gas-stirred ladle with two eccentric nozzles and multiple sensors
}

\author{
Najib Alia $^{1}$ (D) Mika Pylvänäinen $^{2} \cdot$ Ville-Valtteri Visuri $^{3} \cdot$ Volker John $^{1,4} \cdot$ Seppo Ollila $^{5}$
}

Received: 1 June 2018/Revised: 24 September 2018 / Accepted: 29 September 2018/Published online: 1 March 2019

(C) The Author(s) 2019

\begin{abstract}
During ladle stirring, a gas is injected into the steel bath to generate a mixing of the liquid steel. The optimal process control requires a reliable measurement of the stirring intensity, for which the induced ladle wall vibrations have proved to be a potential indicator. An experimental cold water ladle with two eccentric nozzles and eight mono-axial accelerometers was thus investigated to measure the vibrations. The effect of the sensors' positions with respect to the gas plugs on the vibration intensity was analyzed, and experimental data on several points of the ladle were collected for future numerical simulations. It is shown that the vibration root-mean-square values depend not only on process parameters, such as gas flow rate, water, and oil heights, but also on the radial and axial positions of the sensors. The vibration intensity is clearly higher, close to the gas plumes, than in the opposite side. If one of the nozzles is clogged, the vibration intensity close to the clogged nozzle drops drastically ( -36 to $-59 \%$ ), while the vibrations close to the normal operating nozzle are hardly affected. Based on these results, guidelines are provided for an optimized vibration-based stirring.
\end{abstract}

Keywords Ladle metallurgy $\cdot$ Gas stirring $\cdot$ Ladle vibration $\cdot$ Optimal position $\cdot$ Sensor

\section{Introduction}

In ladle treatments, the steel bath is stirred by a gas injected from the bottom of the ladle through one or several purging plugs. The gas stirring promotes melt movement, homogenization, steel-slag reactions, and removal of deoxidation products $[1,2]$. Sometimes, the stirring intensity varies because of gas leakage or plug clogging [3] and makes the controlling of the stirring process difficult. More generally, the main challenge is to find a reliable measurement of the stirring efficiency. The injected gas causes continuous

Najib Alia

alia@wias-berlin.de

1 Weierstrass Institute for Applied Analysis and Stochastics (WIAS), Berlin 10117, Germany

2 Intelligent Machines and Systems, University of Oulu, Oulu 90014, Finland

3 Process Metallurgy Research Unit, University of Oulu, Oulu 90014, Finland

4 Department of Mathematics and Computer Science, Freie Universität Berlin, Berlin 14195, Germany

5 SSAB Europe Oy, Raahe 92101, Finland formation and bursting of gas bubbles in the molten steel, which induces mechanical vibrations to the ladle and the surrounding ladle support where the ladle is placed for the treatment. Therefore, one possibility for the stirring process control is based on the measurements of the ladle wall vibrations [4].

Several studies have been performed on the vibration measurements of laboratory and industrial ladles. Burty et al. [5, 6] studied advanced technique for ladle stirring monitoring, including vibrations sensors and derived an optimal vibration range to monitor the inclusion removal rate. Behera et al. [7] implemented a stirring control system, which is based on the measurements of vibrations, and concluded that a vibration-based monitoring of the ladle furnace enabled a reduction of $20 \%$ and $10 \%$ in argon gas and aluminum consumption, respectively. Yenus et al. [8] have studied multivariate analysis methodologies to analyze three-axial vibration signals measured from the physical laboratory-scale cold model. Based on the principal component analysis used to unveil the structure of the measured data [9], they concluded that the contribution of vibration along the $x, y$, and $z$ directions was almost equal. In a later study, Yenus et al. [10, 11] applied a similar 
methodology for a laboratory-scale and plant-scale vacuum tank degasser. Nadif et al. [12] and Pylvänäinen et al. [13] also analyzed the vibration measurements on vacuum tank degassers and their relationship with process parameters. Another research direction focuses on the oscillation characteristics of argon-oxygen decarburization (AOD) $[14,15]$, where vibrations are studied experimentally and numerically on laboratory and industrial vessels, to improve the design and the process of AOD converters.

Table 1 summarizes the main configurations studied in the literatures. If some of these studies tested different locations for the accelerometers, a typical practice seems to use one sensor, whose position is chosen after preliminary trials or with maintenance-related criteria (ease of access and mounting). An alternative approach consists in using multiple sensors. The simultaneous measurements at different radial and axial positions may improve the understanding of vibrations signals, especially in the case of eccentric gas injection nozzles. Indeed, besides being common in industry, eccentric nozzles generate plumes which are not axial symmetrical and whose effect on the ladle walls is therefore expected to be not symmetrical as well. In this regard, the use of multiple sensors at different locations together with eccentric nozzles appears relevant.

This paper aims at providing new insights concerning the optimal number and position of vibrations sensors for industrial stirring monitoring. More specifically, the study focuses on a laboratory-scale ladle with two eccentric nozzles and several accelerometers covering the ladle wall.

\section{Materials and methods}

\subsection{Physical model}

The investigation was performed on a 1:5 scaled physical model of a $150 \mathrm{t}$ industrial steelmaking ladle made of acrylic glass and containing two eccentric gas nozzles. To obtain kinematic similarity, air, water, and rapeseed oil were used to represent argon, liquid steel, and slag, respectively. While water is a standard choice to simulate liquid steel, several types of oil have a similar kinematic viscosity to that of the slag and can be therefore chosen. The main reasons for using rapeseed oil are its price and its availability. The similarity criteria are based on the kinematic similarity of the gas plume, as expressed by the Froude number $F r$ in Eq. (1) [16]:

$$
F r=\frac{\rho_{\mathrm{g}} u_{\mathrm{g}}^{2}}{\rho_{1} g d},
$$

where $\rho_{\mathrm{g}}$ is the gas density; $\rho_{\mathrm{l}}$ is the liquid density; $u_{\mathrm{g}}$ is the gas velocity; $d$ is the characteristic length of the injection device; and $g$ is the gravitational acceleration. The relationship between the experimental and industrial flow rates of gas $Q^{\prime}$ and $Q$ is given by the following equation [16]:

$$
Q^{\prime}=\lambda^{2.5} Q
$$

where $\lambda$ is the scale ratio. For more details about the physical model, the reader is referred to Ref. [17]. Figure 1 illustrates the main characteristics of the water tank model. The main dimensions are given in Table 2 .

Similarly to the actual ladle, the diameter of the vessel increases from the bottom to the top, and a pouring lip is present on one side of the tank. However, the diameter increase is rather limited (3\% slope). In addition, it is assumed that the presence of the lip does not significantly influence the stirring pattern and the vibrations of the ladle wall. Therefore, the results obtained on this experimental setup are expected to be comparable to existing data from the literature.

In order to study the influence of different process parameters on vibrations, three water heights, six gas flow levels, two oil thicknesses, and three nozzles cases were

\begin{tabular}{|c|c|c|c|c|}
\hline References & Physical model & Industrial ladle & Nozzle & Vibrations sensors number, axis, and position \\
\hline Burty et al. $[5,6]$ & $\swarrow(\mathrm{LF})$ & $\swarrow(\mathrm{LF})$ & 1 & 1 sensor on ladle wall \\
\hline Behara et al. [7] & - & $\swarrow(\mathrm{LF})$ & 2 eccentric & 1 sensor on ladle car \\
\hline Yenus et al. [8] & $レ(\mathrm{LF})$ & - & 1 centered & 1 triaxial on ladle wall (tested at 3 different heights) \\
\hline Yenus et al. $[10,11]$ & $\boldsymbol{レ}(\mathrm{VTD})$ & $\boldsymbol{レ}(\mathrm{VTD})$ & 2 eccentric & 1 triaxial (tested on ladle, support, and tank wall) \\
\hline Nadif et al. [12] & $\boldsymbol{レ}(\mathrm{VTD})$ & $\boldsymbol{レ}(\mathrm{VTD})$ & 2 eccentric & 1 sensor (tested with 3 axis and at 3 positions) \\
\hline Pylvänäinen et al. [13] & - & $\boldsymbol{\nu}(\mathrm{VTD})$ & 2 eccentric & 1 horizontal and 1 vertical on tank \\
\hline Odenthal et al. [14] & $\boldsymbol{\nu}(\mathrm{AOD})$ & $\boldsymbol{\nu}(\mathrm{AOD})$ & - & 1 sensor at vessel bottom \\
\hline Wuppermann et al. [15] & $\boldsymbol{\nu}(\mathrm{AOD})$ & $\boldsymbol{\nu}(\mathrm{AOD})$ & - & 1 mono-axial at vessel bottom \\
\hline Present work & $\mathscr{( L F )}$ & - & 2 eccentric & 8 horizontal sensors (different radial and axial positions) \\
\hline
\end{tabular}

Table 1 Studies on vibration measurements of gas-stirred vessels in metallurgy

$L F$ Ladle furnace; $V T D$ vacuum tank degasser 
(a)

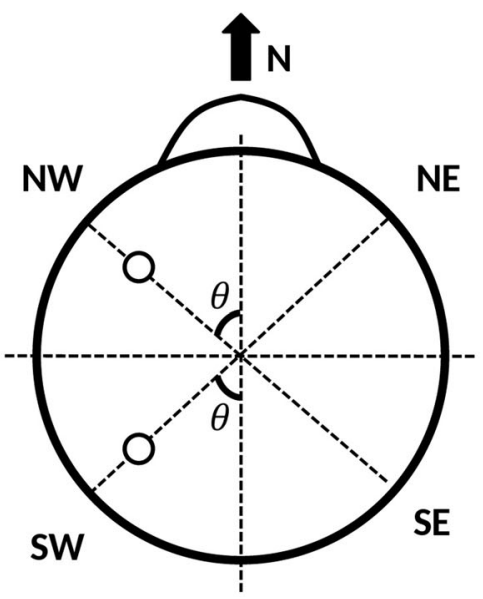

(b)

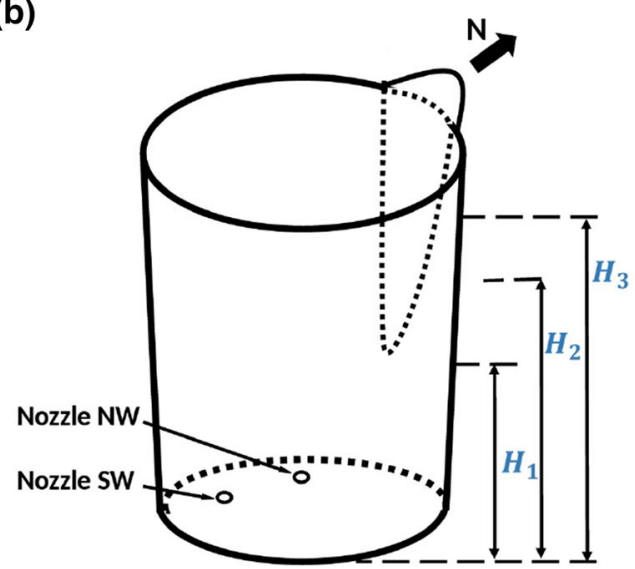

Fig. 1 Schematic of water tank model with orientations' convention, nozzles' position, and three water heights used in the campaign $\left(H_{1}=32.5\right.$ $\mathrm{cm}, H_{2}=54 \mathrm{~cm}$, and $\left.H_{3}=65 \mathrm{~cm}\right)$. a Top view; b perspective view

Table 2 Water tank dimensions

\begin{tabular}{ll}
\hline Model height & $78 \mathrm{~cm}$ \\
Top diameter & $58.5 \mathrm{~cm}$ \\
Bottom diameter & $54 \mathrm{~cm}$ \\
Liquid & Water \\
Liquid height & $65 \mathrm{~cm}$ \\
Slag & Rapeseed oil \\
Slag height & $3 \mathrm{~cm}$ \\
Nozzles diameter & $1.8 \mathrm{~mm}$ \\
Distance from nozzle center & $15 \mathrm{~cm}$ \\
Angle $\theta$ & $48^{\circ}$ \\
Total gas flow rate & $3-57 \mathrm{~L} / \mathrm{min}$
\end{tabular}

studied, corresponding to a total of 108 configurations; the values of these parameters are reported in Table 3 .

The lowest $H_{1}$ was chosen to be below the level of the lip and is half of the highest level $H_{3}$, which corresponds to the nominal value of the physical model. $H_{2}$ is an intermediary value between the lowest and highest water level tested. The range of the gas flow rates allows to cover soft, medium, and strong bubbling. As in the common industrial practice, the same flow rate value is applied to both nozzles in the configuration where they operate simultaneously. In this case, the total gas flow rates are $10,20,30,40,50$, and $60 \mathrm{~L} / \mathrm{min}$. The oil levels allow to see how the presence or absence of oil influences the vibrations measurements. Although the slag layer is always present in industrial practice, its thickness variation is usually small and might not significantly impact the vibration levels in comparison with other process parameters. Choosing more drastic oil thicknesses may facilitate the detection and observation of the effect of slag on the vibrations measurements. Finally, the three
Table 3 Configurations of the experimental campaign

\begin{tabular}{ll}
\hline Water height & $H_{1}=32.5 \mathrm{~cm}$ \\
& $H_{2}=54 \mathrm{~cm}$ \\
& $H_{3}=65 \mathrm{~cm}$ \\
$Q$ for each nozzle & $5,10,15,20,25,30 \mathrm{~L} / \mathrm{min}$ \\
Oil level & $0 \mathrm{~cm}$ (without oil) \\
& $3 \mathrm{~cm}$ (with oil) \\
Nozzles & Nozzle NW only \\
& Nozzle SW only \\
& Both nozzles \\
\hline
\end{tabular}

nozzles configurations correspond to three operating conditions which can be found in industrial practice: The normal situation, where both nozzles operate together with the same flow rate, and a critical situation, where one of the nozzle is completely clogged (zero flow rate) while the other works correctly, and vice versa.

\subsection{Vibrations sensors}

In order to measure the vibrations simultaneously at different positions of the ladle wall, eight mono-axial accelerometers of type MMF KS80D have been used. They were calibrated using a calibrator PCB 394C06, which produces vibrations of known amplitude $\left(9.90 \mathrm{~m} / \mathrm{s}^{2} \pm\right.$ $1.5 \%)$ and frequency $(159.1 \mathrm{~Hz} \pm 0.1 \mathrm{~Hz})$, to ensure that their nominal sensitivity is correct $(100 \mathrm{mV} / \mathrm{g} \pm 5 \%)$. The measurement range of the sensors is $\pm 55 \mathrm{~g}$.

Existing results from the literatures have shown that the vibrations have the highest amplitude on the horizontal axis and perpendicular to the ladle wall $[10,12]$. In this study, the sensors measure the vibrations horizontally, almost perpendicular to the ladle wall (3\% slope). 
PVC blocks were specially manufactured with an appropriate shape to fit on the outside tank wall. The vibration sensors are screwed on these blocks, which are then glued with corresponding PVC glue on the tank wall. The total mass of one accelerometer with its mounting PVC block is $99 \mathrm{~g}$ and is negligible in comparison with the ladle mass. Therefore, it is assumed that the eight mounted sensors do not impact the mechanical and vibrational behavior of the ladle.

Two levels of sensors with four sensors per level were mounted on the ladle wall: one at $h_{1}=25 \mathrm{~cm}$, and one at $h_{2}=54 \mathrm{~cm}$. The positions are chosen according to two criteria: the vertical level to the liquid free surface, and the radial distance to the nozzles and, consequently, to the gas plumes. Concerning the vertical position, the level corresponding to $h_{1}$ is a 'deep' position close to the ladle bottom and to the gas nozzles. Note that the sensors located there are always below the liquid free surface, i.e., $h_{1}<H_{i}$, $i=1,2,3$. The second level, $h_{2}$, allows to study the vibrations of the sensors, when they are either above the free surface $\left(H_{1}<h_{2}\right)$, on the same level as the free surface $\left(H_{2}=h_{2}\right)$, or below it $\left(H_{3}>h_{2}\right)$. The last case also allows to compare the signals of the sensors located far below and just below the free surface. Concerning the radial distance to the nozzles, two sensors are located as close as possible to the two nozzles, while two others are diametrically opposed. Finally, none of the sensors is mounted on the pouring lip of the model.

The accelerometers are referred to according to their position relatively to the lip of the ladle (which points at the North N, Fig. 1). Their locations, as well as a photograph of the real water tank during the experimental campaign, are illustrated in Fig. 2.

\subsection{Signal treatment}

For each of the 108 tested cases, 5 min with a sampling frequency of $25.6 \mathrm{kHz}$ is recorded for the eight sensors simultaneously using a data acquisition module, leading to a large amount of data.

The recording process is as follows:

1. Initially, the ladle is at rest during $30 \mathrm{~s}$;

2. at the 30th second, the gas valves are opened, and the flow rate reaches its target value very quickly;

3. the stirring runs at a constant gas flow rate during 3 $\min (180 \mathrm{~s})$;

4. at the 210th second, the gas valves are closed, and the bath returns to rest until the end of the recording (300th second).

The signal processing was performed with the commercial software Matlab ${ }^{\mathrm{TM}}$. Using the calibration signal, a correction factor was derived for each accelerometer and applied to all the raw signals. Then, the offsets were computed and subtracted from the measurements, so that all the signals have an offset equal to 0 . These two preprocessing steps ensure the comparability of the measurements.

An appropriate quantity to represent the vibrations amplitude or intensity is the root-mean-square (RMS) value of the acceleration signals (in $\mathrm{m} / \mathrm{s}^{2}$ ) [18]. This quantity has been computed from the preprocessed vibration data to make the analysis of this study.

Other types of signal treatment, e.g., frequency analysis, are under current study to complete the exploitation of the gathered data.

Although the stirring takes place between the 30th and the 210th second, the root-mean-square values are (a)

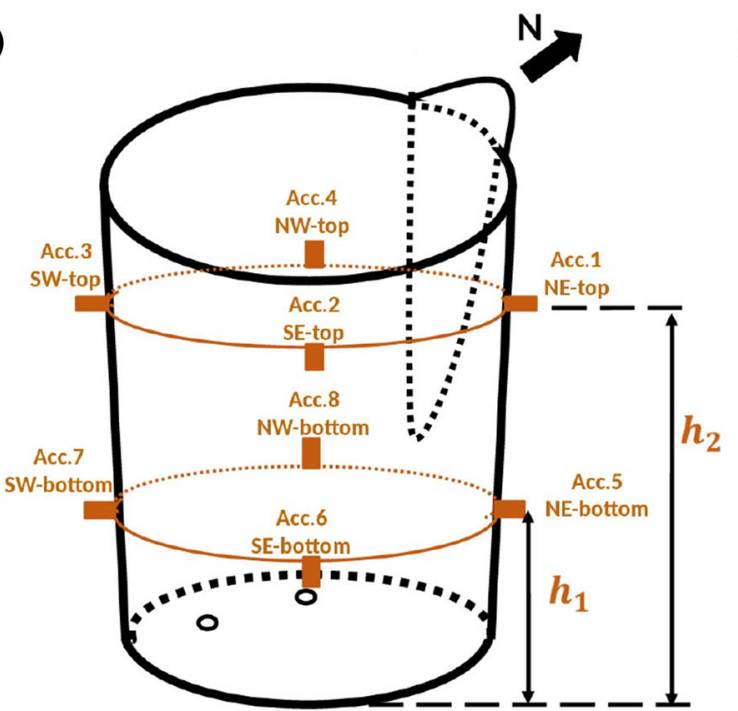

(b)

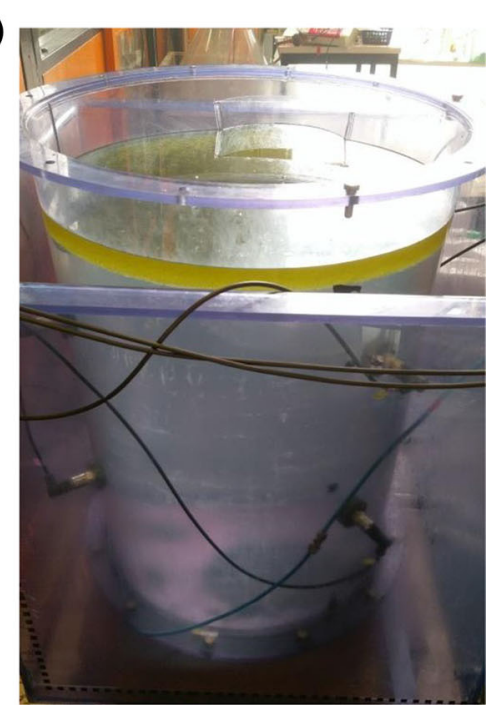

Fig. 2 Water tank model with oil layer. a Position and designation of accelerometers $\left(h_{1}=25 \mathrm{~cm}\right.$ and $\left.h_{2}=54 \mathrm{~cm}\right) ; \mathbf{b}$ real water tank model. Two sensors at $h_{1}$ can be seen clearly and two sensors at $h_{2}$ are behind the cables 
computed between 40 and $200 \mathrm{~s}$ in order to avoid transitional phases and to capture a stirring as constant as possible.

Figure 3 shows two examples of vibrations measurements.

\section{Results and discussion}

\subsection{Relationship between vibration and process parameters}

\subsubsection{Vibration RMS versus gas flow rate}

In the nominal case, corresponding to the physical similarity with the industrial ladle $\left(H_{3}\right.$, presence of oil, two nozzles operating), the evolution of the vibration level of the eight sensors with respect to the gas flow rate is illustrated in Fig. 4.

As reported in the studies [10, 12, 13, 19, 20], the vibrations amplitude increases with the gas flow rate. The relationship between the vibration level and the gas flow rate is nonlinear, rather logarithmic. It is interesting to note

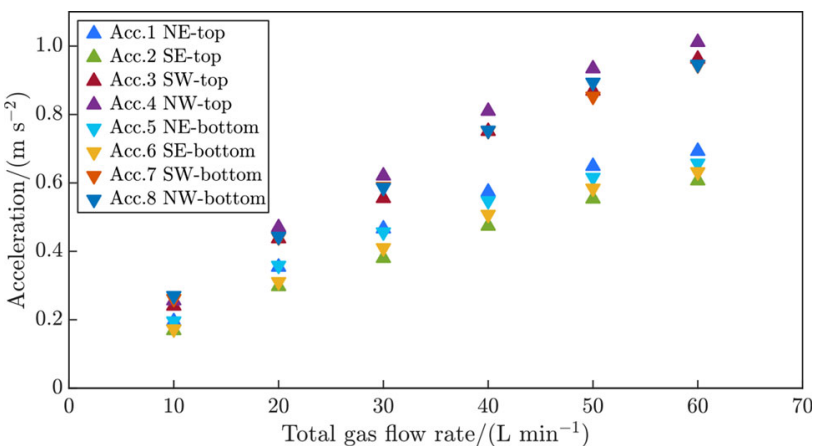

Fig. 4 RMS values of temporal acceleration signals between 40-200 s versus total gas flow rate $\left(H_{3}\right.$, with oil layer and two nozzles operating)

that this shape is similar to the ones obtained in Ref. [10], although different geometries and materials are used in the physical model.

In Fig. 4, it can be clearly seen that the vibrations RMS values of the four accelerometers close to the nozzles, i.e., sensors 3, 4, 7, and 8 are significantly higher than the sensors which are diametrically opposed to them $(1,2,5$, and 6), respectively. In addition, they also
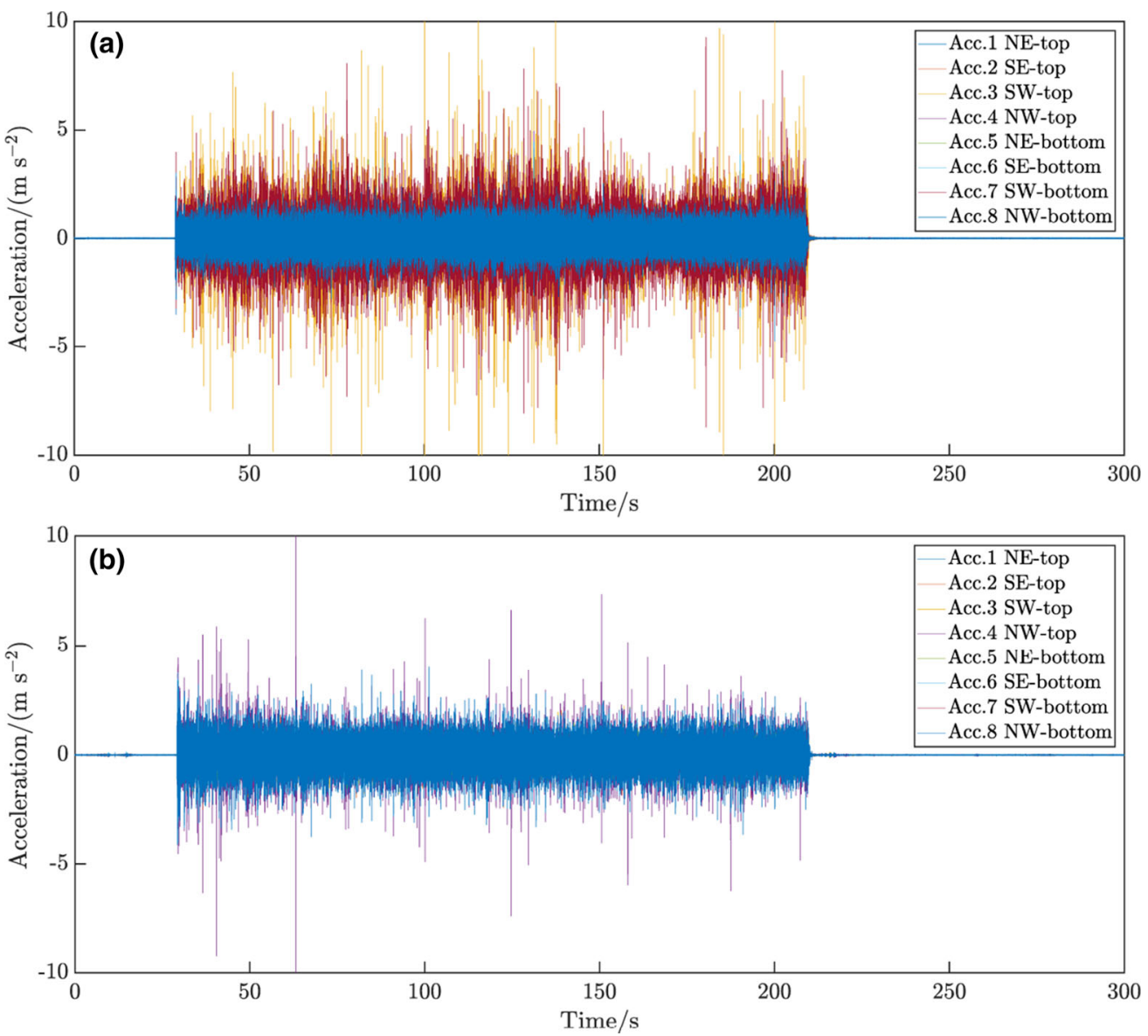

Fig. 3 Example of measurement obtained. a Nozzle SW only, $H_{3}, Q=25 \mathrm{~L} / \mathrm{min}$, without oil; b Nozzle NW only, $H_{2}, Q=15 \mathrm{~L} / \mathrm{min}$, with oil 
increase faster with the gas flow rate than the opposite sensors. This indicates that the radial position of the sensors plays a major role in the measured vibration intensity.

The comparison between the top and bottom sensors which are close to the nozzles ( 3 vs 7 and 4 vs 8 ) shows that the vibrations amplitude in the top tends to be slightly stronger than the ones in the bottom.

In the other cases $\left(H_{1}\right.$ and $H_{2}$, without oil, one nozzle operating), the results are similar; they are not reproduced here. Only the vibrations amplitude is different.

\subsubsection{Vibration RMS versus water height}

In the case where $Q$ is fixed, and no oil layer is employed; the evolution of the vibration RMS values with respect to the water height is given in Fig. 5 for the bottom and top sensors.

It can first be seen that the vibrations of the bottom sensors tend to increase with higher water heights. This conclusion confirms the results obtained by Nadif et al. [12], where different experimental configurations with the same order of magnitude as those in the present work have been conducted. Regarding the top sensors, it is more difficult to distinguish any trend. It should be noted, however, that in the particular case $H_{1}$, i.e., when the sensors are located above the free surface, the vibrations are much higher than those in the cases $\mathrm{H}_{2}$ and $\mathrm{H}_{3}$. Once the sensors are at the same level $\left(H_{2}\right)$ or below the free surface $\left(\mathrm{H}_{3}\right)$, the vibrations drop. Since the height difference between $\mathrm{H}_{2}$ and $\mathrm{H}_{3}$ is quite small, the vibrations amplitude seems to be hardly affected by a small water height change.

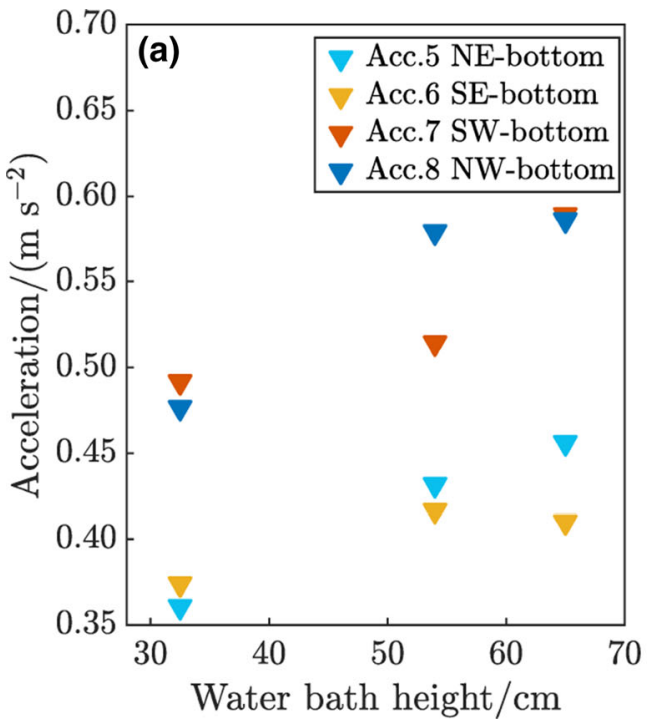

By comparing the case $H_{1}$ between top and bottom sensors in Fig. 5, it can be further noticed that the signals measured by the top accelerometers are $30-90 \%$ higher than those measured by the bottom ones, even if they are relatively far from the gas plumes (e.g., diametrically opposed). This has been observed for all gas flow rates and nozzle configurations employing $H_{1}$, including the case where the oil layer is added.

It is still an open question why the sensors located above the free surface have these higher vibrations levels. Unlike the bottom sensors, they are not facing the fluid and are subjected only to free vibrations of the structure. One possible reason could be that they are less dampened than the bottom sensors, leading to stronger vibrations amplitude.

These cases suggest that the vibrations amplitude strongly depends on the vertical position of the sensors relatively to the water height. In order to only capture stirring-related vibrations, it is recommended to place the sensors in the height of the bath rather than above the free surface level, i.e., along the gas plumes, between the ladle bottom, and the open eyes.

\subsubsection{Vibration RMS versus presence of oil layer}

Figure 6 illustrates the vibrations intensity with and without oil layer, in the nominal configuration.

It can be observed that the top sensors are slightly more sensitive to the slag height than the bottom sensors, although this is not significant. More generally, as it has also been seen in the other configurations, the vibrations tend to slightly increase in the presence of the oil layer. Since this increase is not significant when the oil height is increased from 0 to $3 \mathrm{~cm}$, small fluctuations of oil heights

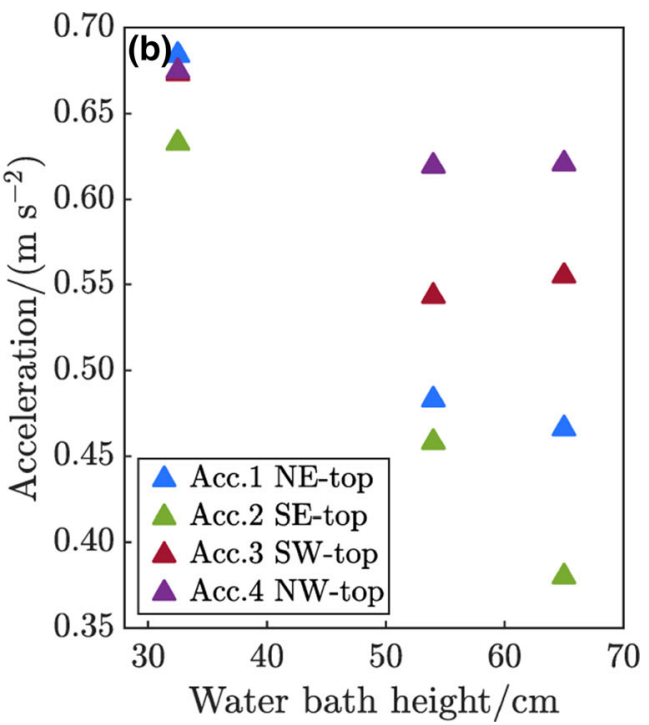

Fig. 5 RMS values versus water height $(Q=30 \mathrm{~L} / \mathrm{min}$, without oil layer and two nozzles operating). a Bottom sensors; b top sensors 

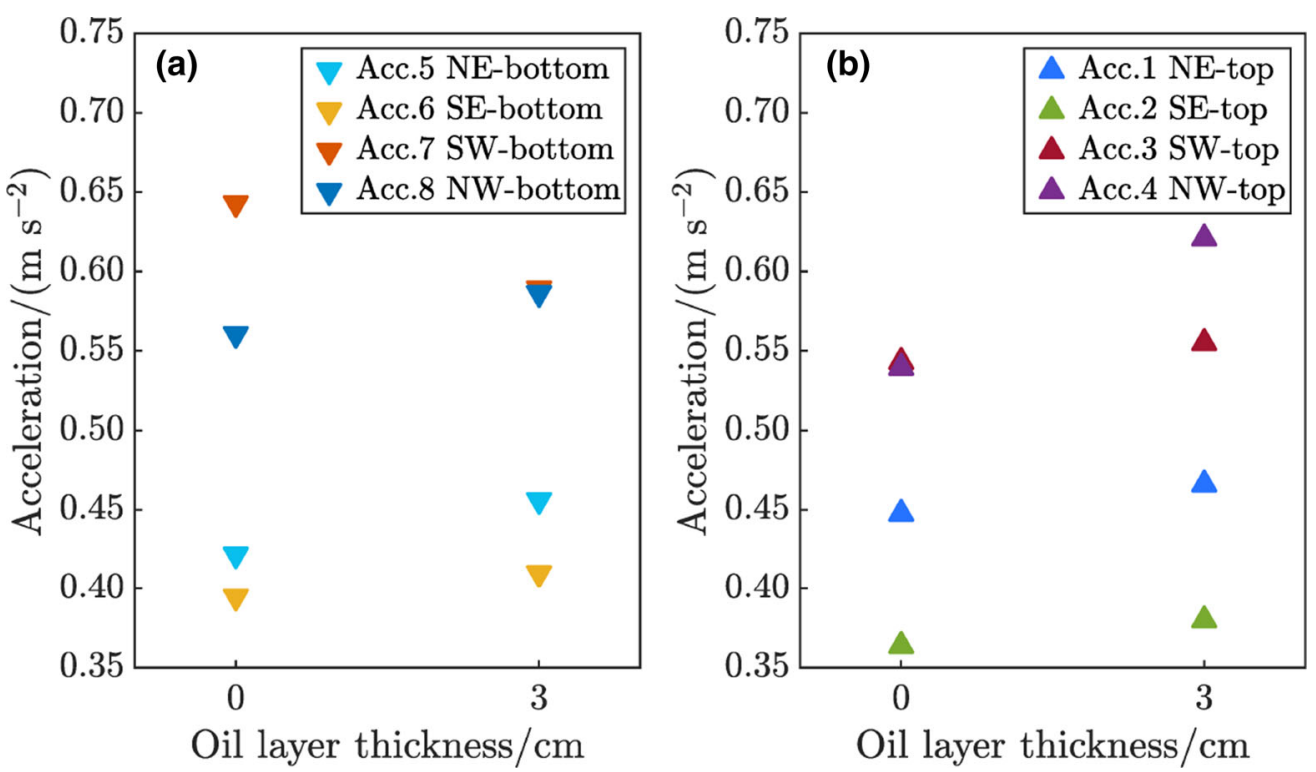

Fig. 6 RMS values versus oil layer ( $Q=30 \mathrm{~L} / \mathrm{min}, H_{3}$ and two nozzles operating). a Bottom sensors; b top sensors

would be even more difficult to capture in the vibrations measurements. Even if, in industrial practice, the slag is much thicker and heavier than the parameters used in this experiment, thanks to the physical similarity, the same conclusion might be applicable for industrial vibrations measurements.

\subsection{Detection of nozzle clogging using several sensors}

\subsubsection{Sensors close to nozzles}

Since the previous results have shown that the strongest vibration intensity is obtained with the sensors close to the two gas plumes, only these four sensors are considered here: 3 and 7 (SW-top and SW-bottom) and 4 and 8 (NWtop and NW-bottom). Figure 7 shows the difference between the three operating conditions: both nozzles SW and NW, nozzle SW only, and nozzle NW only.

Interestingly, one can notice that the vibrations of the sensors SW (respectively, NW) in the case where only nozzle SW (respectively, NW) operates are very similar to their level when both nozzles operate simultaneously. In other words, the vibrations close to one nozzle (e.g., SW) seem to be relatively independent from the operating condition of the other nozzle (e.g., NW). This is an important result, since it makes it easier to distinguish the operating conditions of the two nozzles, by using (at least) one sensor close to each nozzle, or, in other words, close to each gas plume.

Furthermore, the vibrations amplitude of sensors 4 and 8 (NW-top and NW-bottom), when the nozzle NW operates, is close to the one of the sensors 3 and 7 (SW-top and SWbottom) when the nozzle SW operates, at equivalent flow rates.

The differences of RMS amplitudes between the three operating configurations are computed in Table 4. It can be seen that the nozzle clogging results in a significant drop of the RMS value ( -36 to $-59 \%$ ) of the sensors located close to the clogged nozzle, in comparison with its value where both nozzles work normally. Except for low flow rates, the vibrations of the sensors close to the operating nozzle are not affected very much by the clogging of the second nozzle and the absence of its corresponding gas plume (less than $10 \%$ change, for gas flows superior to $15 \mathrm{~L} / \mathrm{min}$ ). With low flow rates, the clogging of one nozzle results in a perceptible drop in the vibration intensity of the sensors close to the operating nozzle.

If only one sensor was used to detect the clogging of a nozzle among several ones, it would have been difficult to identify the reason for a vibration drop: decreasing stirring intensity of the one nozzle (e.g., gas leakage) or the clogging of the other. Using several sensors can be, in this regard, more advantageous.

\subsubsection{Note about other sensors}

Finally, another interesting result, which is related to the four sensors diametrically opposed to the gas plumes and visible in Fig. 8, shows that the vibration levels of all of them can significantly decrease (up to $30 \%$ ) when only one nozzle is operating, in comparison with the case with two working nozzles. Although their vibration level 


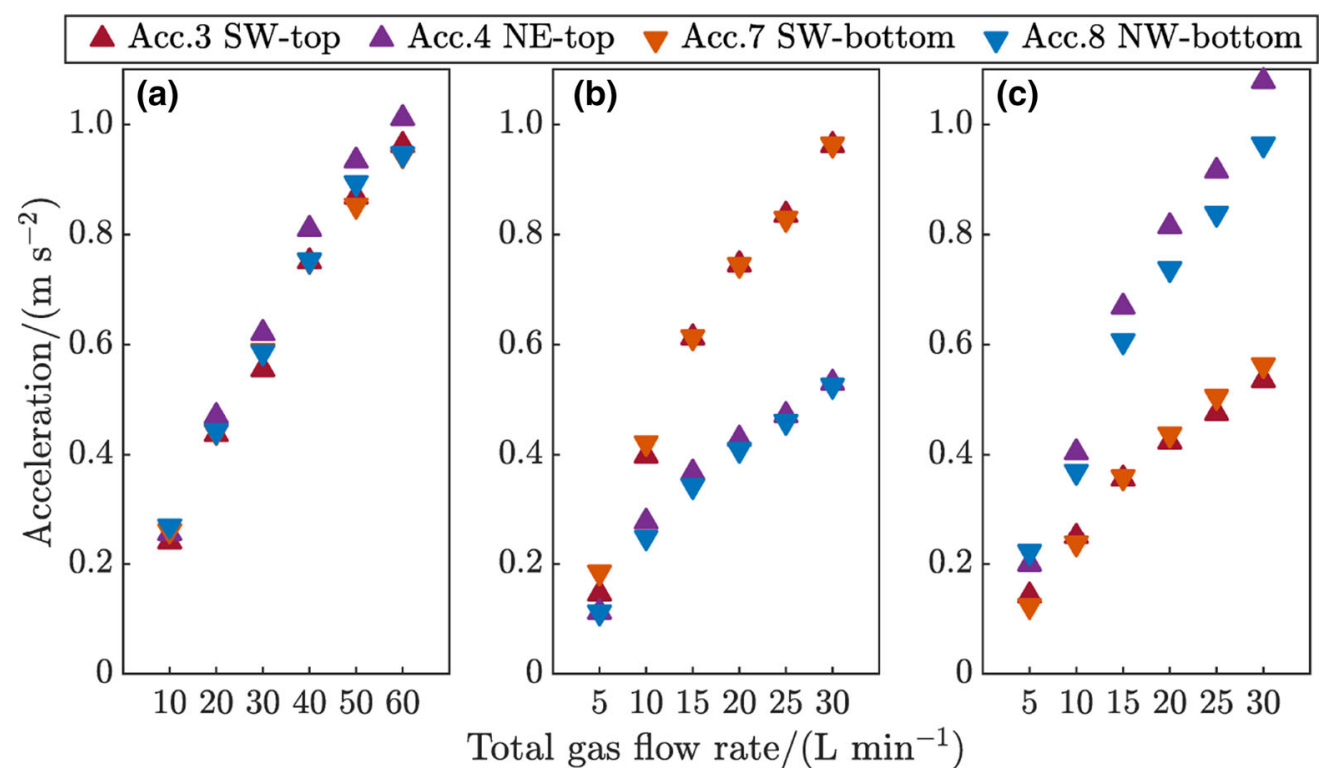

Fig. 7 RMS values of sensors close to nozzles versus total gas flow rate $\left(H_{3}\right.$, with oil layer). a Two nozzles operating; b nozzle SW only; $\mathbf{c}$ nozzle NW only

Table 4 Difference in RMS amplitude between reference case (two operating nozzles) and two cases with nozzle clogging

\begin{tabular}{|c|c|c|c|c|c|c|c|c|}
\hline \multirow[t]{2}{*}{$Q$} & \multicolumn{4}{|c|}{ Nozzle SW operating (NW clogged)/\% } & \multicolumn{4}{|c|}{ Nozzle NW operating (SW clogged) $/ \%$} \\
\hline & SW-top (3) & NW-top (4) & SW-bottom (7) & NW-bottom (8) & SW-top (3) & NW-top (4) & SW-bottom (7) & NW-bottom (8) \\
\hline 5 & -39.4 & -55.9 & -29.4 & -58.5 & -40.8 & -21.9 & -52.6 & -17.8 \\
\hline 10 & -9.0 & -40.8 & -4.6 & -43.9 & -42.7 & -14.0 & -46.2 & -16.7 \\
\hline 15 & 10.4 & -40.9 & 4.1 & -41.4 & -35.8 & 7.7 & -39.0 & 3.5 \\
\hline 20 & -0.7 & -47.1 & -1.0 & -45.7 & -43.6 & 0.6 & -41.9 & -2.1 \\
\hline 25 & -4.0 & -49.5 & -2.8 & -48.5 & -45.3 & -2.0 & -40.7 & -6.2 \\
\hline 30 & 0.0 & -47.5 & 2.0 & -44.4 & -44.4 & 6.7 & -40.4 & 1.8 \\
\hline
\end{tabular}

RMS amplitude $=100 \cdot \frac{\mathrm{RMS}_{i}-\mathrm{RMS}_{\mathrm{ref}}}{\mathrm{RMS}_{\mathrm{ref}}}$

$\mathrm{RMS}_{\text {ref }}$ is RMS of vibrations in reference case (both nozzles operating in Fig. 7a); RMS ${ }_{i}$ refers to RMS of vibrations in the case where only nozzle $i$ operates, $i$ being either SW (Fig. 7b) or NW (Fig. 7c)

always remains lower than those of the four sensors close to the gas plumes, this result can be useful in practice: using a third sensor located far from the gas plumes can give an additional hint on the operating conditions of the nozzles.

\section{Conclusions}

The aim of this study was to provide guidelines for optimizing the number and the placement of accelerometers in industrial application and ladle monitoring systems in order to better identify the operating conditions of gas stirring.
The results show that the vibration RMS values are not only related to usual process parameters, such as the gas flow rate, the water height, and the oil layer thickness, as reported in previous literatures, but they are also strongly dependent on the radial and axial location of the accelerometers. More precisely, the results suggest that the sensors located close to the gas nozzles or purging plugs are able to capture higher intensity levels than the ones which are diametrically opposed. Furthermore, placing the sensors quite far from the bottom of the ladle leads to stronger vibrations. They should also not be placed too high, i.e., above the liquid free surface, in order to better describe the stirring intensity. 


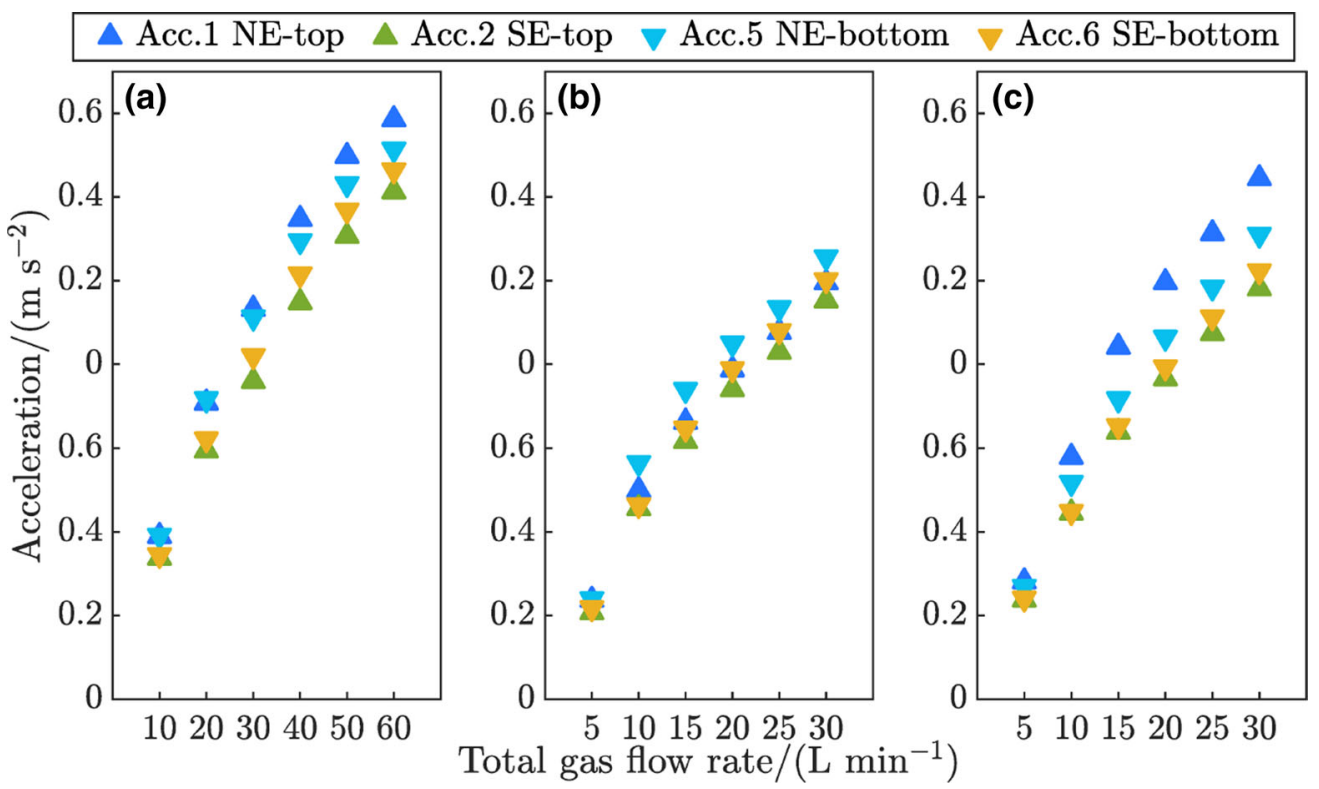

Fig. 8 RMS values of sensors far from nozzles versus total gas flow rate $\left(H_{3}\right.$, with oil layer). a Two nozzles operating; b nozzle SW only; c nozzle NW only

In other words, the recommended positions for each sensor seem to be along the gas plume, between the ladle bottom up to the open eye of the corresponding operating nozzle. This leads to the strongest vibrations levels and helps to estimate more precisely the stirring conditions.

Using several accelerometers, at least one close to each nozzle, can facilitate the measurement of the stirring intensity of the corresponding gas plume, the quantification of a drop in the stirring efficiency (due to gas leakage for example), and the detection of nozzle clogging. Moreover, the stirring intensity and condition of each nozzle can be estimated separately and independently. This knowledge could be used to improve the predictability of process outcome as well as the need for maintenance. An additional third sensor, located this time far from the plume, e.g., diametrically opposed, can also give hints on the operating conditions.

Since a numerical model of gas-induced wall vibrations is currently under development, this laboratory study has also provided experimental measurements at several points of the ladle wall, which can then be advantageously used in the validation of the numerical model.

Acknowledgements N. Alia is grateful for the support of the European Union's Horizon 2020 research and innovation programme under the Marie Skłodowska-Curie Grant Agreement No. 675715 (MIMESIS). V.V. Visuri is grateful for the support of the Finnish Cultural Foundation. The authors are grateful to Eshwar Ramasetti and Riku Mattila, from the Process Metallurgy Research Unit at the University of Oulu, for their valuable help in the experimental campaign, as well as, Jouni Laurila and Konsta Karioja, from the Intelligent Machines and Systems Research Unit, for their substantial contribution to the vibrations measurements and treatment.

Open Access This article is distributed under the terms of the Creative Commons Attribution 4.0 International License (http://crea tivecommons.org/licenses/by/4.0/), which permits unrestricted use, distribution, and reproduction in any medium, provided you give appropriate credit to the original author(s) and the source, provide a link to the Creative Commons license, and indicate if changes were made.

\section{References}

[1] L. Holappa, in: S. Seetharaman, A. McLean, R.I.L. Guthrie, S. Sridhar (Eds.), Treatise on Process Metallurgy, Volume 3 Industrial Processes, Elsevier Oxford, UK, 2014, pp. 301-345.

[2] D. Mazumdar, J.W. Evans, in: Taylor and Francis Group (Eds.), Modeling of Steelmaking Processes, CRC Press, USA, 2009.

[3] P.E. Anagbo, J.K. Brimacombe, A.H. Castillejos, Can. Metall. Quart. 28 (1989) 323-330.

[4] T. Fabritius, P. Kurkinen, P. Mure, J. Härkki, Ironmak. Steelmak. 32 (2005) 113-119.

[5] M. Burty, C. Pusse, C. Bertoletti, P. Wetta, E. Cariola, Rev. Métall. 103 (2006) 493-499.

[6] M. Burty, C. Pusse, D. Sheng, C. Dannert, H. Koechner, L. Sancho, J. Diaz, P. Valentin, C. Bruch, A. Arteaga, EUR 22988 Development of advanced methods for the control of ladle stirring process, European Commission-Technical steel research series, Publications Office of the European Union, Luxembourg, 2007.

[7] N. Behera, A. Wohaishi, R. Subramanian, N. Tewari, R. Bommaraju, in: AISTech Proceedings of the Iron \& Steel Technology Conference II, Indianapolis, USA, 2014, pp. 1423-1432. 
[8] J. Yenus, G. Brooks, M. Dunn, Metall. Mater. Trans. B 47 (2016) 2681-2689.

[9] X.B. Xu, Analysis of bubble flow in metallurgical operations using multivariate statistical techniques, Faculty of E. and Industrial S., Swinburne University of Technology, Australia, 2010.

[10] J. Yenus, G. Brooks, M. Dunn, Z. Li, T. Goodwin, Metall. Mater. Trans. B 49 (2018) 423-433.

[11] J. Yenus, Vibration and sound signal analysis in gas stirred ladles, Faculty of E. and Industrial S., Swinburne University of Technology, Australia, 2017.

[12] M. Nadif, L. Orue, H. Lachmund, H. Abdullah, R. Roessler, EUR 25091-Online control of desulphurisation and degassing through ladle bubbling under vacuum, European Commission Research fund for coal and steel series, Publications Office of the European Union, Luxembourg, 2012.

[13] M. Pylvänäinen, V.V. Visuri, T. Liedes, J. Laurila, K. Karioja, S. Pikkupeura, S. Ollila, T. Fabritius, in: Swerea MEFOS (Ed.), Proceedings of the 5th International Conference on Process
Development in Iron and Steelmaking, Swerea MEFOS, Luleå, Sweden, 2016, pp. 1-9.

[14] H.J. Odenthal, U. Thiedemann, U. Falkenreck, J. Schlueter, Metall. Mater. Trans. B 41 (2010) 396-413.

[15] C. Wuppermann, A. Rückert, H. Pfeifer, H.J. Odenthal, ISIJ Int. 53 (2013) 441-449.

[16] K. Krishnapisharody, G.A. Irons, Metall. Mater. Trans. B 44 (2013) 1486-1498.

[17] T. Palovaara, V.V. Visuri, T. Fabritius, in: Associazione Italiana di Metallurgia (Ed.), Proceedings of the 7th International Congress on Science and Technology of Steelmaking, Associazione Italiana di Metallurgia, Venice, Italy, 2018, pp. 1-10.

[18] M.P. Norton, in: D.G. Karczub (Ed.), Fundamentals of Noise and Vibration Analysis for Engineers, Cambridge University Press, UK, 2003.

[19] R. Minion, C. Leckie, K. Legeard, B. Richardson, Iron steelmaker 25 (1998) 25-31.

[20] Y. Kostetskii, I. Kvasov, I. Degtyarenko, D. Kukui, Russ. Metall. 7 (2009) 595-597. 